Dermatology 2016;232:381

DOI: $10.1159 / 000445739$

\section{Hidradenitis Suppurativa: Terminology}

Jean Revuz

Private practice, Paris, France

Key Words

Hidradenitis suppurativa $\cdot$ Nodules · Tunnels · Terminology

The original paper by Lipsker et al. [1] on a glossary of individual lesions of hidradenitis suppurativa (HS), published online on February 19, 2016, is welcome. The heterogeneity of the disease and the discordances in clinical reports are frequent. So, this partially new terminology should be useful if it gains general approv$\mathrm{al}$; it is not only a glossary, but also a tentative clinical description of lesions.

I would like to comment on two items:

(1) Nodule is described as a 'raised lesion, round, diameter $>10 \mathrm{~mm}$, three-dimensional'. This description fits with some of the HS nodules but it does not represent the most frequent and most typical forms. Indeed, the nodules are usually deep-seated and barely visible; they are however easily palpable although painful. Trying to find 'raised' lesions may lead non-experts to miss some of the most frequent lesions, at least in mild and moderate HS.

(2) Tunnel is described as an 'opening of variable length and depth, ending at the skin surface, and sometimes oozing a fluid; term to be preferred if extension of the lesion beyond the skin and if not related to a skin structure such as pilosebaceous or sweat gland duct; fistulas and sinuses are examples of tunnels'.

So, in this description, the word 'tunnel' includes all open lesions (usually with spontaneous or provoked discharge), particularly fistulas and sinus tracts. For common sense, a 'tunnel' has two openings; as a matter of fact, tunnels (with two openings) are very specific for this disease: joining two former abscesses, sometimes more than $10 \mathrm{~cm}$ in length, with a linear or angular shape, and frequently a discharge through both orifices. They are a kind of signature of HS and, most of the time, an indication for surgery as they do not heal under medical treatment.

Lesions with one opening - I usually call them 'fistulas' - have not the same prognostic and the same resistance to medical treatment; therefore they should be called differently.

The problems encountered in this work may come from the fact that pictures were used and that several of the typical lesions of HS cannot be described properly by sight only.

\section{Disclosure Statement}

The author declares no conflicts of interest.

\section{Reference}

1 Lipsker D, Severac F, Freysz M, Sauleau E, Boer J, Emtestam L, Matusiak $€$, Prens E, Velter C, Lenormand C, Meyer N, Jemec GB: The ABC of hidradenitis suppurativa: a validated glossary on how to name lesions. Dermatology 2016;232:137-142.

\section{KARGER}

E-Mail karger@karger.com www.karger.com/drm
(C) 2016 S. Karger AG, Base

$1018-8665 / 16 / 2323-0381 \$ 39.50 / 0$
Jean Revuz

11, chaussée de la Muette

FR-65016 Paris (France)

E-Mail revuz.jean@wanadoo.fr 